\title{
Total medical costs of treating femoral neck fracture patients with hemi- or total hip arthroplasty: a cost analysis of a multicenter prospective study
}

\author{
P. T. P. W. Burgers ${ }^{1}$ - M. Hoogendoorn ${ }^{2}$ - E. A. C. Van Woensel ${ }^{1}$. \\ R. W. Poolman ${ }^{3}$ M. Bhandari ${ }^{4}$ - P. Patka ${ }^{5}$ E. M. M. Van Lieshout ${ }^{1}$ • \\ on behalf of the HEALTH trial investigators
}

Received: 26 May 2015 / Accepted: 4 January 2016 / Published online: 28 January 2016

(C) The Author(s) 2016. This article is published with open access at Springerlink.com

\begin{abstract}
Summary The aim of this study was to determine the total medical costs for treating displaced femoral neck fractures with hemi- or total hip arthroplasty in fit elderly patients. The mean total costs per patient at 2 years of follow-up were $€ 26,399$. These results contribute to cost awareness.

Introduction The absolute number of hip fractures is rising and increases the already significant burden on society. The aim of this study was to determine the mean total medical costs per patient for treating displaced femoral neck fractures with hemi- or total hip arthroplasty in fit elderly patients.

Methods The population was the Dutch sample of an international randomized controlled trial consisting of femoral neck
\end{abstract}

Electronic supplementary material The online version of this article (doi:10.1007/s00198-016-3484-z) contains supplementary material, which is available to authorized users.

E. M. M. Van Lieshout

e.vanlieshout@erasmusmc.nl

1 Trauma Research Unit Department of Surgery, Erasmus MC, University Medical Center Rotterdam, P.O. Box 2040, 3000 CA Rotterdam, The Netherlands

2 Institute for Medical Technology Assessment, Erasmus University Rotterdam, P.O. Box 1738, 3000 DR Rotterdam, The Netherlands

3 Department of Orthopaedic Surgery, Joint Research, OLVG, P.O. Box 95500, 1090 HM Amsterdam, The Netherlands

4 Department of Clinical Epidemiology and Biostatistics, McMaster University, HSC 2C, 1200 Main Street West, Hamilton, ON L8N 3Z5, Canada

5 Department of Emergency Medicine, Erasmus MC, University Medical Center Rotterdam, P.O. Box 2040, 3000 CA Rotterdam, The Netherlands fracture patients treated with hemi- or total hip arthroplasty. Patient data and health care utilization were prospectively collected during a total follow-up period of 2 years. Costs were separated into costs for hospital care during primary stay, hospital costs for clinical follow-up, and costs generated outside the hospital during rehabilitation. Multiple imputations were used to account for missing data.

Results Data of 141 participants (mean age 81 years) were included in the analysis. The 2-year mortality rate was $19 \%$. The mean total cost per patient after 10 weeks of follow-up was $€ 15,216$. After 1 and 2 years of follow-up the mean total costs were $€ 23,869$ and $€ 26,399$, respectively. Rehabilitation was the main cost determinant, and accounted for $46 \%$ of total costs. Primary hospital admission days accounted for $22 \%$ of the total costs, index surgery for $11 \%$, and physical therapy for $7 \%$.

Conclusions The main cost determinants for hemi- or total hip arthroplasty after treatment of displaced femoral neck fractures $(€ 26,399$ per patient until 2 years) were rehabilitation and nursing homes. Most of the costs were made in the first year. Reducing costs after hip fracture surgery should focus on improving the duration and efficiency of the rehabilitation phase.

Keywords Arthroplasty $\cdot$ Cost analysis $\cdot$ Femoral neck fracture $\cdot$ Hip fracture $\cdot$ Medical costs

\section{Introduction}

The major complication of osteoporosis is the clinical manifestation of a hip fracture. Based upon global trends and demographic changes the worldwide number of hip fractures is expected to be over 7.3 million patients in the year $2050[1,2]$. 
In The Netherlands the number of patients sustaining a hip fracture has more than doubled since 1981 to almost 19,000 patients in 2012 [3]. Almost $60 \%$ of all proximal femoral fractures concern the femoral neck and $80 \%$ of these fractures are displaced [4]. The Garden classification is frequently used for describing femoral neck fractures in the elderly [5]. Garden type 3 and 4 represent displaced fractures. Femoral neck fractures can be treated using a non-operative approach, internal fixation, or arthroplasty. The arthroplasty group includes hemiarthroplasty and total hip arthroplasty. Approximately $62 \%$ of patients aged 65 years or older are primarily treated with arthroplasty; hemiarthroplasty is performed in this group in $78 \%$ of patients on average [6]. Different insights into the preferred treatment of femoral neck fractures are the subject of ongoing international debate [7]. An international survey revealed that $75 \%$ of the responding surgeons prefer primary arthroplasty for patients over 60 years of age with a displaced fracture. For patients under 60 years of age with a displaced fracture (Garden type 3 or 4), hemiarthroplasty was preferred by $11 \%$ and $25 \%$ of respondents, respectively [7]. Although initial costs for arthroplasty are higher than for internal fixation, arthroplasty has been proven to be a cost-effective therapy [8-11].

According to data of the Dutch Ministry of Health, Welfare and Sports, hip fracture-associated crude total cost in The Netherlands was $€ 471.5$ million in 2011 [12]. Insight into health care use and associated costs is gaining importance as the burden of health care costs threatens to exceed the financial resources available. Such insight may reveal options for cutting down health care expenses. Although surgeons are expected to have a general idea about the costs for treatments they provide, these data are not easily available [13-15]. Recently, data became available on the total medical costs of femoral neck fracture patients treated with internal fixation in The Netherlands [16]. To the best of our knowledge, detailed analysis of the costs of hemi- or total hip arthroplasty for femoral neck fractures in The Netherlands has not been published before. Therefore, the aim of this study was to provide a detailed overview of the costs consumed by patients with a displaced femoral neck fracture that was treated with hemi- or total hip arthroplasty.

\section{Patients and methods}

This cost study was conducted as a cohort study alongside the Dutch sample of the HEALTH trial (hip fracture evaluation with alternatives of total hip arthroplasty versus hemiarthroplasty, NCT00556842), an international randomized controlled trial comparing total hip arthroplasty and hemiarthroplasty on revision surgery and quality of life in patients with a displaced femoral neck fracture. The local medical research ethics committees of all participating centers approved the study. Informed consent was obtained from all individual participants included in the study.

\section{Population}

In The Netherlands, 14 hospitals participated and enrolled 150 patients between December 15, 2008 and February 14, 2011. Patients were eligible if they: (1) were adults aged $\geq 50$ years, (2) had a (radiologically confirmed) displaced femoral neck fracture (ICD-10 code S72.0; Garden type 3 and 4) after a low energy impact and no other major trauma, (3) were operated within 3 days of presenting to the emergency room, and (4) were ambulatory pre-fracture (with or without aid). Patients provided informed consent. Patients were excluded if they: (1) were not suitable for treatment with arthroplasty (i.e., inflammatory arthritis, rheumatoid arthritis, pathologic fracture, or severe osteoarthritis of the hip), (2) had infection or retained hardware around the affected hip, (3) had a bone metabolism disorder other than osteoporosis, (4) were moderately or severely cognitively impaired pre-fracture, (5) had dementia or Parkinson's disease severe enough to compromise the rehabilitation process, or (6) were not likely to be able to complete follow-up.

\section{Treatment and follow-up}

Medical optimization was warranted for all included patients before surgery. Within $72 \mathrm{~h}$ after presenting to the emergency department, patients were treated with hemi- or total hip arthroplasty. The exact treatment including material choice (cemented or uncemented and unipolar or bipolar prosthesis) was left to the treating surgeon. Antibiotic prophylaxis and thromboprophylaxis were prescribed to all patients according to local protocols. Post-operative weight bearing was as tolerated and early mobilization was encouraged. All patients were screened and treated for osteoporosis if deemed necessary. Follow-up measurements were performed at 10 weeks and at $6,9,12,18$, and 24 months after the primary surgery.

\section{Cost measurement}

This study included the following categories for hip-related costs: (1) hospital costs during primary hospital stay, including emergency department visit, diagnostic evaluations, surgery, and admission days; (2) hospital costs during follow-up, including diagnostic evaluations, outpatient clinic visits, diagnosis and treatment of adverse events, revision surgery, and admission days; and (3) non-hospital costs of rehabilitation and aids.

Data on health care use were collected prospectively at each scheduled follow-up contact and at the close-out visit at the end of the study. Data were collected from the study case 
report forms (items are listed in electronic supplementary material (ESM) Supplemental Table 1) and from the patient's hospital file. At each follow-up contact, patients were asked to complete a questionnaire on their health care use. This questionnaire was a customized version of the "Trimbos and iMTA questionnaire on Costs associated with Psychiatric illness" (Tic-P), which has been validated for use in health care cost studies [16, 17]. An English version of the TicP questionnaire is available online [18]. The questionnaire included questions on stay in a hospital, rehabilitation center or nursing facility, number of contacts with an intramural medical specialist or paramedical worker during admission and follow-up, medication use, comorbidity and use of walking aids. Missing data were collected during the close-out visit at each hospital.

The total number of consumption units per cost category was multiplied by the unit prices. All unit prices were indexed with the national consumer price index to 2012 and are presented in Table 1. Costs for the index surgery, including time spent in the operating room, theater personnel, overhead, anesthesia, and implant material and general equipment, was provided by two teaching hospitals and one academic hospital. Data from the teaching hospitals were averaged in order to obtain a realistic estimate of the average prices in the participating teaching hospitals. Reference cost prices of most other health care resources were derived from the Dutch manual on cost research, methods and standard costs in economic health care evaluations [19]. The NZa (Nederlandse Zorgautoriteit; Dutch Health care Authority) is the Dutch market regulator in care and advises the Minister on health care costs. This institute provided the unit prices for intramural diagnostic procedures. Costs of medication were derived from the CVZ (College voor zorgverzekeringen; Health Care Insurance Board), which is online accessible on www.medicijnkosten.nl. Costs of rehabilitation aids were obtained from a local home care firm that is a representation of national practice. Costs of aids were calculated according to the annuity method, applying an interest rate of $4.5 \%$ and a 10 -year write-off period. With over $90 \%$ of the patients in the study being retired, the costs for production losses were considered of limited importance for this population, and were thus excluded. Home care was also excluded, since it was impossible to determine which proportion of the total home care received was due to the hip fracture. As done previously in a similar study on internal fixation of femoral neck fractures, costs of osteoporosis screening were included in radiology/diagnostic studies costs, costs of visits to an osteoporosis specialist were included in outpatient clinic-visit costs, and costs for osteoporosis treatment were included in medication costs.

\section{Statistical analysis}

Data were analyzed using SPSS (version 20.0, SPSS Inc., Chicago, IL, USA). Replacement of missing values for cost items was done with multiple imputations following the predictive mean matching method, using ten imputations [20]. The following variables were included in the imputation model: sex, age, ASA at baseline, walking independently at baseline, treatment, costs of initial surgery, and all other cost categories at 10 weeks and at 6, 9, 12, 18, and 24 months. Each of the ten complete datasets were further analyzed by nonparametric bootstrapping using 1000 bootstraps per dataset [21]. The $95 \%$ confidence interval around the mean costs was determined by taking the 2.5 th and the 97.5 th percentile of these bootstrap replications. Costs were calculated for the total study population.

\section{Results}

\section{Demographics}

The 14 participating hospitals registered 592 consecutive patients with a femoral neck fracture, of whom 181 were eligible and 150 (25\%) subsequently gave informed consent (Fig. 1). One patient withdrew consent immediately, one patient died before surgery, and seven patients were treated with internal fixation rather than arthroplasty. A total of 141 patients remained for the current cost analysis, of whom 74 were treated with hemiarthroplasty and 67 with a total hip arthroplasty. The mean age was 81 (SD 7; range 57-100) years, 2 patients ( $1 \%$; both females) were younger than 60 years of age. A total of 96 patients $(68 \%)$ were female. The mean age was 80 (SD 8; range 57-100) years for females and 81 (SD 6; range 6991) years for males. No patients $(0 \%)$ had ASA class 1 or class 5, 67 (48\%) patients had ASA class 2, $72(51 \%)$ ASA class 3 , and $2(1 \%)$ ASA class 4 . A total of $136(97 \%)$ patients were not institutionalized before the fracture, and $102(72 \%)$ patients were independently ambulatory before the fracture.

\section{Clinical outcome and health care consumption}

The mean duration of hospital admission was 10 days (SD 8). One patient with a complicated clinical course was discharged at 90 days after the initial surgery. Within 14 days after surgery, $87 \%(N=123)$ of the patients were discharged. The discharge destination was a rehabilitation or nursing facility in $56 \%$ of patients, and $44 \%$ of patients went to their own house. Median stay per patient was 10 days (SD 28) in a rehabilitation facility, 14 days (SD 42) in a nursing facility, and 18 days (SD 62) in an elderly home. During rehabilitation, patients had a mean of 52 (SD 5) physical therapy sessions per patient.

A total of 118 adverse events (AEs) occurred; 77 patients (55\%) had no $\mathrm{AE}$ at all. The most frequent AEs were a subsequent fracture $(N=19 ; 13 \%)$, a superficial wound infection $(N=11 ; 8 \%)$, and dislocations $(N=10 ; 7 \%)$. Less than 
Table 1 Sources and unit costs of health care resources

\begin{tabular}{|c|c|c|c|c|}
\hline Cost categories & Unit & Source of consumption data & Source of value & Unit price $(€)$ \\
\hline \multicolumn{5}{|l|}{ Hospital costs - primary stay } \\
\hline Emergency department visit & Visit & Hospital registry & Cost manual $^{\mathrm{a}}$ & 160.34 \\
\hline \multicolumn{5}{|l|}{ Radiology/diagnostic modalities } \\
\hline X-ray & X-ray & Hospital registry & $\mathrm{NZa}^{\mathrm{b}}$ & 54.14 \\
\hline CT-scan pelvis & CT-scan & Hospital registry & $\mathrm{NZa}^{\mathrm{b}}$ & 238.25 \\
\hline MRI scan pelvis & MRI scan & Hospital registry & $\mathrm{NZa}^{\mathrm{b}}$ & 274.16 \\
\hline Ultrasound & Ultrasound & Hospital registry & $\mathrm{NZa}^{\mathrm{b}}$ & 86.07 \\
\hline DEXA scan & DEXA scan & Hospital registry & $\mathrm{NZa}^{\mathrm{b}}$ & 114.52 \\
\hline Skeletal scintigraphy & Scintigraphy & Hospital registry & $\mathrm{NZa}^{\mathrm{b}}$ & 194.37 \\
\hline \multicolumn{5}{|l|}{ Surgery } \\
\hline Surgeon & Hour & Study registry (CRF) & Cost manual $^{\mathrm{a}}$ & $143.88^{\mathrm{c}} / 109.37^{\mathrm{d}}$ \\
\hline Operating room ${ }^{\mathrm{e}}$ & Hour & Study registry (CRF) & Hospital/industry data ${ }^{\mathrm{f}}$ & $738.60^{\mathrm{c}} / 885.00^{\mathrm{d}}$ \\
\hline \multicolumn{5}{|l|}{ Equipment and implant } \\
\hline Cemented hemiarthroplasty & Operation & Study registry (CRF) & Hospital/industry data ${ }^{\mathrm{f}}$ & $1362.00^{\mathrm{c}} / 1197.73^{\mathrm{d}}$ \\
\hline Cemented total hip arthroplasty & Operation & Study registry (CRF) & Hospital/industry data ${ }^{\mathrm{f}}$ & $1465.75^{\mathrm{c}} / 1684.45^{\mathrm{d}}$ \\
\hline Uncemented total hip arthroplasty & Operation & Study registry (CRF) & Hospital/industry data ${ }^{\mathrm{f}}$ & $\mathrm{NA} / 2041.80^{\mathrm{d}}$ \\
\hline Admission days & Day & Study registry (CRF) & Cost manual $^{\mathrm{a}}$ & $610.57^{\mathrm{c}} / 461.91^{\mathrm{d}}$ \\
\hline \multicolumn{5}{|l|}{ Hospital costs-follow-up } \\
\hline Radiology/diagnostic modalities & & & & As described above \\
\hline Outpatient clinic visits & Visit & Hospital registry + questionnaire ${ }^{\mathrm{g}}$ & Cost manual $^{\mathrm{a}}$ & $136.98^{\mathrm{c}} / 67.96^{\mathrm{d}}$ \\
\hline \multicolumn{5}{|l|}{ Adverse events } \\
\hline Medication $^{\mathrm{h}}$ & Dose per day & Hospital registry/questionnaire ${ }^{\mathrm{g}}$ & $\mathrm{CVZ}^{\mathrm{i}}$ & Variable \\
\hline Emergency & Visit & Hospital registry & Cost manual $^{\mathrm{a}}$ & 160.34 \\
\hline Brace & Piece & Hospital registry/questionnaire ${ }^{\mathrm{g}}$ & Hospital/industry data ${ }^{\mathrm{f}}$ & 440.39 \\
\hline Admission days & Day & Study registry (CRF) & Cost manual $^{\mathrm{a}}$ & $610.57^{\mathrm{c}} / 461.91^{\mathrm{d}}$ \\
\hline \multicolumn{5}{|l|}{ Revision surgery } \\
\hline Surgeon & Hour & Study registry (CRF) & Cost manual $^{\mathrm{a}}$ & $143.88^{\mathrm{c}} / 109.37^{\mathrm{d}}$ \\
\hline Operating room $^{\mathrm{e}}$ & Hour & Study registry (CRF) & Hospital/industry data ${ }^{\mathrm{f}}$ & $738.60^{\mathrm{c}} / 885.00^{\mathrm{d}}$ \\
\hline \multicolumn{5}{|l|}{ Equipment and implant } \\
\hline Cemented hemiarthroplasty & Operations & Study registry (CRF) & Hospital/industry data ${ }^{\mathrm{f}}$ & $1362.00^{\mathrm{c}} / 1197.73^{\mathrm{d}}$ \\
\hline Cemented total hip arthroplasty & Operations & Study registry (CRF) & Hospital/industry data ${ }^{\mathrm{f}}$ & $1465.75^{\mathrm{c}} / 1684.45^{\mathrm{d}}$ \\
\hline Uncemented total hip arthroplasty & Operations & Study registry (CRF) & Hospital/industry data ${ }^{\mathrm{f}}$ & $\mathrm{NA} / 2041.80^{\mathrm{d}}$ \\
\hline Cup revision & Operations & Study registry (CRF) & Hospital/industry data ${ }^{\mathrm{f}}$ & 773.09 \\
\hline Open fenestration/bursectomy & Operations & Study registry (CRF) & Hospital/industry data ${ }^{\mathrm{f}}$ & 524.20 \\
\hline Open reduction (OR) & Operations & Study registry (CRF) & Hospital/industry data ${ }^{\mathrm{f}}$ & 333.96 \\
\hline Closed reduction (ER) & Operations & Study registry (CRF) & Hospital/industry data ${ }^{\mathrm{f}}$ & 160.34 \\
\hline Antibiotic beads & Operations & Study registry (CRF) & Hospital/industry data ${ }^{\mathrm{f}}$ & 324.83 \\
\hline Admission days & Days & Study registry (CRF) & Hospital/industry data ${ }^{\mathrm{f}}$ & $610.57^{\mathrm{c}} / 461.91^{\mathrm{d}}$ \\
\hline Medication $^{\mathrm{j}}$ & Dose per day & Hospital registry/questionnaire ${ }^{\mathrm{g}}$ & $\mathrm{CVZ}^{\mathrm{i}}$ & NA \\
\hline \multicolumn{5}{|c|}{ Costs related to rehabilitation/changes in living situation } \\
\hline \multicolumn{5}{|l|}{ Rehabilitation center/nursing home } \\
\hline Elderly home & Days & Patient questionnaire ${ }^{\mathrm{g}}$ & Cost manual $^{\mathrm{a}}$ & 95.57 \\
\hline Nursing home & Days & Patient questionnaire ${ }^{\mathrm{g}}$ & Cost manual $^{\mathrm{a}}$ & 252.73 \\
\hline Rehabilitation clinic & Days & Patient questionnaire ${ }^{\mathrm{g}}$ & Cost manual $^{\mathrm{a}}$ & 361.04 \\
\hline Home nursing day & Days & Patient questionnaire $\mathrm{g}^{\mathrm{g}}$ & Cost manual $^{\mathrm{a}}$ & 46.72 \\
\hline Physical therapy (outpatient) & Hour & Patient questionnaire $\mathrm{g}^{\mathrm{g}}$ & Cost manual $^{\mathrm{a}}$ & \\
\hline Physical therapy & Session & Patient questionnaire ${ }^{\mathrm{g}}$ & Cost manual $^{\mathrm{a}}$ & 38.23 \\
\hline \multicolumn{5}{|l|}{ Use of aids } \\
\hline Crutches & Day & Patient questionnaire ${ }^{\mathrm{g}}$ & Home care firm ${ }^{\mathrm{k}}$ & 0.07 \\
\hline Walker & Day & Patient questionnaire ${ }^{\mathrm{g}}$ & Home care firm ${ }^{\mathrm{k}}$ & $0.08-0.15$ \\
\hline Wheelchair & Day & Patient questionnaire ${ }^{\mathrm{g}}$ & Home care firm ${ }^{\mathrm{k}}$ & 0.27 \\
\hline
\end{tabular}


Table 1 (continued)

\begin{tabular}{lllll}
\hline Cost categories & Unit & Source of consumption data & Source of value & Unit price $(€)$ \\
\hline Electric scooter & Day & Patient questionnaire & Home care firm & 0.70 \\
Extra bed & Day & Patient questionnaire & Home care firm & 1.22 \\
Extra toilet facilities & Day & Patient questionnaire & Home care firm & $0.10-0.20$ \\
Extra shower facilities & Day & Patient questionnaire & Home care firm & $0.10-0.18$ \\
\hline
\end{tabular}

Reference unit costs anno 2012 were used, or costs were adjusted to 2012 costs by using the national consumer price index

$N A$ not applicable

${ }^{a}$ Cost manual - manual on cost research, methods and standard costs in economic health care evaluations, version 2010 [16]

${ }^{\mathrm{b}} \mathrm{NZa}$; Nederlandse Zorgautoriteit (Dutch Health care Authority) standard costs

${ }^{\mathrm{c}}$ Academic hospital

${ }^{\mathrm{d}}$ General hospital

${ }^{\mathrm{e}}$ Including operating room personnel, anesthesia, and overhead costs

${ }^{\mathrm{f}} \mathrm{Hospital} /$ industry data; costs were requested from one academic hospital, three regional hospitals, and one surgical equipment and implant firm. Means were calculated and used as an estimation of the real costs in all participating sites

${ }^{g}$ Patient questionnaire — customized version of the "Trimbos and iMTA questionnaire on costs associated with psychiatric illness" [17]

${ }^{\mathrm{h}}$ Mainly antibiotics and in-hospital thrombosis profylaxis

${ }^{\mathrm{i}} \mathrm{CVZ}$ - standard prices were used as described by the CVZ (College voor zorgverzekeringen; Health Care Insurance Board), online available on www. medicijnkosten.nl

${ }^{\mathrm{j}}$ Hip fracture-related medication only (i.e., pain medication and anti-osteoporosis medication; see ESM Supplemental Table 2 for details)

${ }^{\mathrm{k}}$ Home care firm; costs of aids were requested from a home care firm and costs per day were calculated based on the calculated daily annuity. These costs were used as an estimation of the real costs in all participating patients

ten patients had other AEs including pulmonary embolism, urinary tract infection, delirium, or decubitus. Eighteen revimyocardial infarction, cerebral vascular accident, pneumonia, sion surgeries were performed in ten patients (Table 2).

Fig. 1 Flow-chart of patient enrollment process.

*Patients could meet more than one exclusion criterion

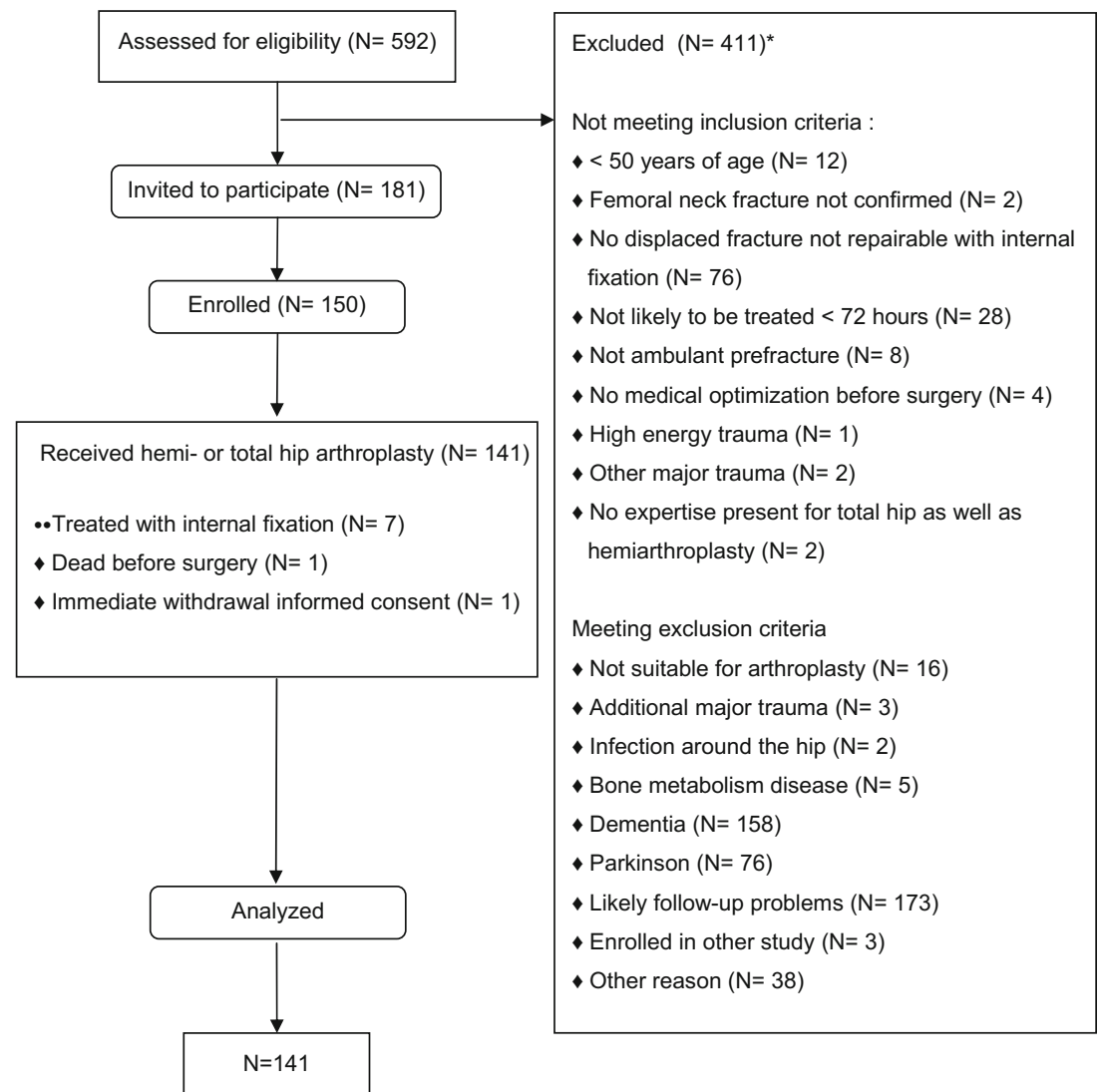


Table 2 List of revision surgeries performed

\begin{tabular}{|c|c|c|c|c|}
\hline & Revision surgery 1 & Revision surgery 2 & Revision surgery 3 & Revision surgery 4 \\
\hline Patient 1 & Conversion to THA & Closed reduction ED & Closed reduction ED & Closed reduction ED \\
\hline Patient 2 & Arthrotomy and joint lavage & Arthrotomy and joint lavage & Arthrotomy and joint lavage & \\
\hline Patient 3 & Closed reduction ED & Closed reduction ED & Plate fixation periprosthetic frx & \\
\hline Patient 4 & Closed reduction OR & Closed reduction ED & & \\
\hline Patient 5 & Conversion to THA & & & \\
\hline Patient 6 & Open reduction & & & \\
\hline Patient 7 & Closed reduction ED & & & \\
\hline Patient 8 & Arthrotomy & & & \\
\hline Patient 9 & Conversion to THA & & & \\
\hline Patient 10 & Closed reduction OR & & & \\
\hline
\end{tabular}

$T H A$, total hip arthroplasty; $E D$, emergency department; $O R$, operating room

Dislocation was treated ten times; seven closed reductions were done in the emergency department, two in the operating room. One patient underwent an open reduction. Three conversions from hemiarthroplasty to total hip arthroplasty were performed. One patient suffered three dislocations after the conversion. One patient underwent an arthrotomy and joint lavage three times to treat a deep infection. One periprosthetic fracture was treated with plating. The 10 -week mortality was $5 \%(N=7)$, the 1 -year mortality was $11 \%(N=16)$, and the 2 year mortality was $19 \%(\mathrm{~N}=27)$. Patients died mainly due to cancer $(N=9)$, cardiovascular diseases $(N=6)$, neurological diseases $(N=3)$, and the bone cement implantation syndrome $(N=2)$. The mean duration of follow-up was 22 months (SD 9).

\section{Costs}

ESM Supplemental Table 3 shows the fraction of patients who used health care and the volume of health care use per user. These data were not imputed. Table 3 shows the calculated mean costs for used health care after multiple imputations of the missing data. The overall percentage of missing data was $17.8 \%$ and the relative efficiency of the multiple imputations was 0.98 . In the first 10 weeks after the fracture the mean total costs was $€ 15,216$, which was $58 \%$ of the total costs. The most important cost category was primary hospital stay accounting for $€ 9026$. From this category, costs were predominantly related to hospital admission (€5732) and index surgery (€2915). Other important costs were incurred for rehabilitation facilities and nursing homes (€4707).

At 1 year of follow-up, the mean total costs per patient was $€ 23,869$ (95\% CI $€ 19,157-€ 30,136$ ), this was $90 \%$ of the overall total costs. Fifty-five percent of costs were spent on rehabilitation and changes in living situation with a total amount of $€ 13,138$. Rehabilitation centers/nursing homes $(€ 11,694)$ and physical therapy at the outpatient clinic $(€ 1340)$ were the main cost determinants. After 2 years of follow-up, the total rehabilitation-related costs $(€ 14,429)$ still accounted for $55 \%$ of the total costs. The hospital costs for follow-up almost doubled from $€ 1705$ ( $7 \%$ of the total costs) after 1 year to $€ 2943$ (11\%) after 2 years of follow-up. The main items were costs related to adverse events which increased by $181 \%$ from $€ 581$ to $€ 1052$ and a $204 \%$ increase in costs for revision surgery from $€ 480$ to $€ 980$ (Fig. 2).

\section{Discussion}

The mean total costs per patient after treatment with hemi- or total hip arthroplasty for femoral neck fracture were $€ 23,869$ $(95 \% \mathrm{CI} € 19,157-€ 30,136)$ at 1 year and $€ 26,399(95 \% \mathrm{CI}$ $€ 21,101-€ 33,213)$ at 2 years after a fracture.

These costs are in line with the range of $€ 12,952$ to $€ 43,671$ (as adjusted to 2012) found in literature [8-10, 22-27]. This broad range can be explained by different variables used in the studies. All studies were performed in western countries, but with different health care systems, mean length of hospital stay, reference costs, and rehabilitation facilities. The populations studied had a relatively small sample size ranging from 32 to 180 patients. One study, involving 19,808 patients, used a Markov decision model [22]. Although most of the costs are generated in the first year, the two studies with the lowest costs had a follow-up of 1 year [23, 25], not taking into consideration the late and costly complications. One study [9] did not include treatment with hemiarthroplasty and two studies only reviewed the costs for patients treated with hemiarthroplasty $[23,24]$. Also, previous studies used different types of costs e.g., in-hospital costs only [8], the included populations differed in age, or included only women [25]. Results of the current study correspond best with the results of the two largest studies (adjusted costs $€ 29,834$ and $€ 29,807$, respectively), both including both types of arthroplasty [10, 22].

In addition, from a prospective cohort study of 10,275 Dutch persons, the estimated incremental costs of medical care were $\$ 9540$ (adjusted to $€$ in 2012 : $€ 11,715$ ) in the first 
Table 3 Mean costs of femoral neck fracture patients treated with hemi- or total hip arthroplasty $(N=141)$

\begin{tabular}{|c|c|c|c|}
\hline Cost categories & Cost until 10 weeks $(€)$ & Costs until 1 year $(€)$ & Costs until 2 years $(€)$ \\
\hline \multicolumn{4}{|l|}{ A) Hospital costs - primary stay } \\
\hline Emergency department visit & $160(160-160)$ & $160(160-160)$ & $160(160-160)$ \\
\hline Radiology/diagnostic modalities & $219(206-232)$ & $219(206-232)$ & $219(206-232)$ \\
\hline Surgery & $2,915(2,798-3,023)$ & $2,915(2,798-3,023)$ & $2,915(2,798-3,023)$ \\
\hline Admission days & $5,732(4,452-7,966)$ & $5,732(4.452-7,966)$ & $5,732(4,452-7,966)$ \\
\hline Total & $9,026(7,706-11,295)$ & $9,026(7,706-11,295)$ & $9,026(7,706-11,295)$ \\
\hline \multicolumn{4}{|l|}{ B) Hospital costs-follow-up } \\
\hline Radiology/diagnostic modalities & $115(103-128)$ & $240(212-270)$ & $344(278-427)$ \\
\hline Outpatient clinic visits & $120(109-133)$ & $297(263-336)$ & $416(355-494)$ \\
\hline Adverse events & $200(66-392)$ & $581(280-1,056)$ & $1,052(568-1,781)$ \\
\hline Revision surgery & $396(61-990)$ & $480(112-1,100)$ & $980(345-1,940)$ \\
\hline Medication & $82(74-92)$ & $106(93-121)$ & $151(125-182)$ \\
\hline Total & $914(499-1,541)$ & $1,705(1,102-2,563)$ & $2,943(1,894-4,308)$ \\
\hline \multicolumn{4}{|c|}{ C) Costs related to rehabilitation/changes in living situation } \\
\hline Rehabilitation center/nursing home & $4,707(3,627-5,874)$ & $11,694(8,132-16,350)$ & $12,240(8,542-17,008)$ \\
\hline Physical therapy (outpatient) & $549(470-640)$ & $1,340(1,162-1,537)$ & $1,975(1,627-2,370)$ \\
\hline Use of aids & $20(17-25)$ & $105(78-139)$ & $214(166-270)$ \\
\hline Total & $5,276(4,200-6,467)$ & $13,138(9,486-17,956)$ & $14,429(10,461-19,552)$ \\
\hline D) Total costs & $15,216(13,051-18,323)$ & $23,869(19,157-30,136)$ & $26,399(21,101-33,213)$ \\
\hline
\end{tabular}

Costs are presented as mean costs at each follow-up moment with $95 \%$ uncertainty interval between brackets

The data have been imputed. If a patient had not consumed health care, costs for that item were recorded as $€ 0$

year after a hip fracture and $\$ 1017(€ 1248)$ in the subsequent year [28]. These incremental costs are comparable with the $€ 14,844$ (first year) and $€ 2529$ (subsequent year) found in the current study. De Laet et al. [28] found higher costs, but that study did not include detailed costs of adverse events, revision surgeries, and costs of diagnostic modalities. The

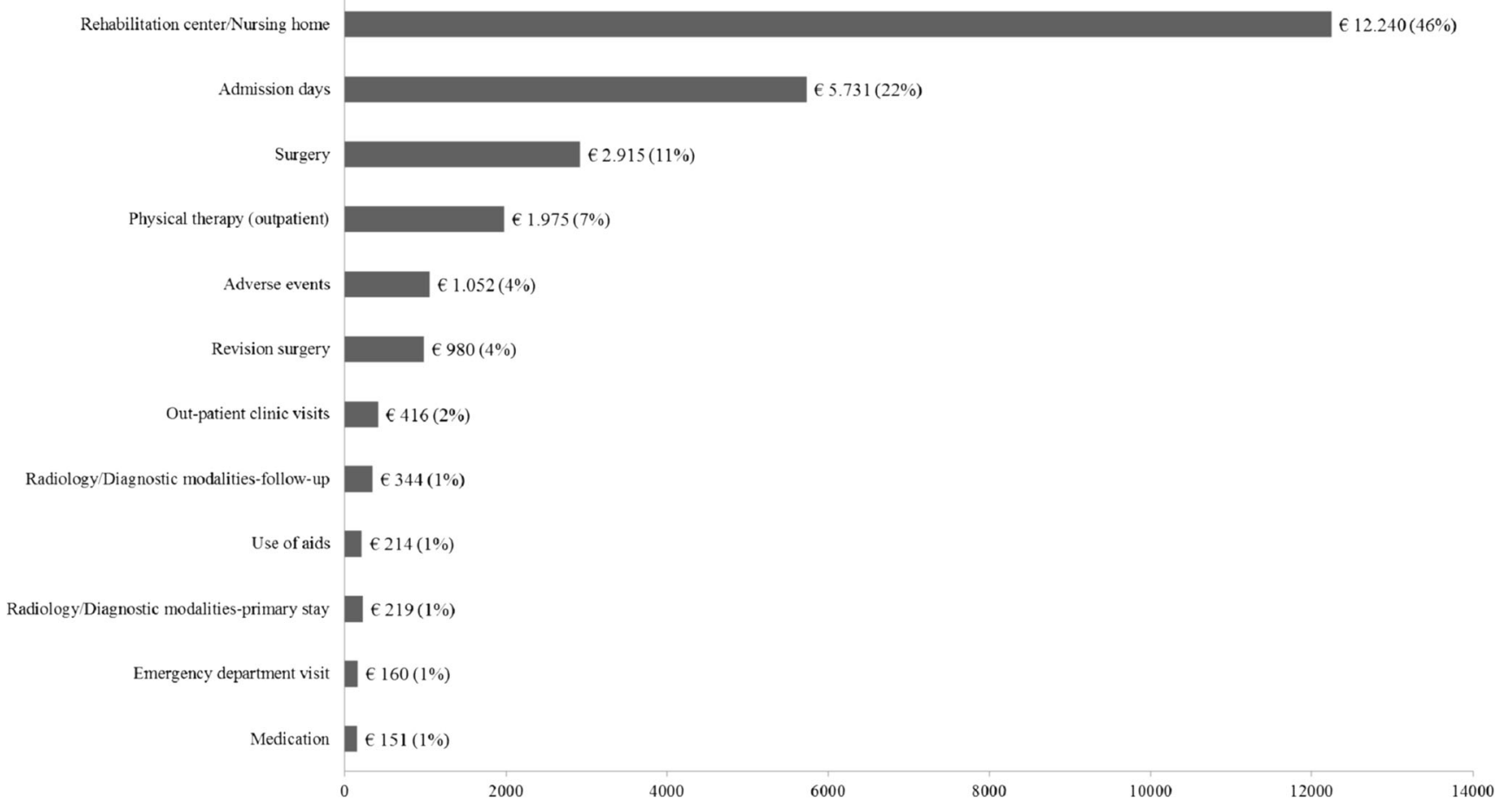

Fig. 2 Relative contribution of costs categories to the total treatment costs of patients until 2 years of follow-up 
in-depth method of our study can be considered more specific as the total costs are presented in more detail.

Recently, a similar study was published involving Dutch elderly patients with a femoral neck fracture (50 years or older) who were primarily treated with internal fixation [16]. Both studies had the same design and used identical research methods, questionnaires, statistics, and resources, making it suitable for direct comparison. After two years of follow-up the costs, adjusted to 2012 for the total internal fixation group were $€ 20,368$ (original data: $€ 19,425 ; 95 \%$ CI $€ 5,237-€ 58$, 874). The relative contributions of the different cost categories were very comparable with respect to rehabilitation ( $46 \%$ of total costs for arthroplasty and $49 \%$ for internal fixation) and hospital admission days (both $22 \%$ ), with higher absolute costs in the current arthroplasty study. These differences can be explained by the generally older population in the arthroplasty group based on baseline characteristics. In the current study, the mean age was 10 years older ( 81 versus 71), patients were more often ASA 3-4 (54 versus $13 \%$ ), used aids pre-fracture more often ( 28 versus $13 \%$ ), and had a displaced fracture more often (100 versus $46 \%$ ). It is likely that older patients are admitted to a rehabilitation facility more often longer. Moreover, the mean number of hospital admission days (10 versus 7 days) was longer in the arthroplasty group. Subgroup analysis of 67 patients $(27 \%)$ who underwent revision to arthroplasty after primary internal fixation resulted in adjusted costs of: $€ 28,031$ ( $€ 26,733$; $95 \%$ CI $€ 9465-€ 80$, 029), which exceeds the costs of primary arthroplasty. This emphasizes the need to carefully select primary treatment for hip fractures as conversion from internal fixation to arthroplasty is even more costly than primary arthroplasty.

This study had some limitations. First, the population has been selected, based upon the eligibility for arthroplasty. Therefore it is a specific subset of the total population which presented to the emergency department of the participating hospitals. The patients were relatively healthy, fit, and most were independent walkers before the fracture. Patients with dementia or Parkinson's disease were excluded, but these patients represent a substantial part of the general hip fracture population. These patients may have complex needs and incur higher costs, consequently leading to an underestimation of the mean costs presented. Costs are based on Dutch prices and may vary depending on the health care system used. However, by comparing with published costs from other Western countries, we showed that the results are applicable to other settings as well. Secondly, the actual costs are expected to be even higher as costs for pre-hospital care, costs for routine blood analysis at the emergency department and wards, and perioperative consultation by other medical specialists and, although not routinely applied, forensic autopsy were not included. On the other hand, the number of visits for follow-up and X-rays are lower in general practice than in a trial setting. Also, the amounts used in the cost price manuals used may differ from the actual costs. However, these costs are not expected to be substantial. Finally, costs for home care and general practitioner (GP) visits were not included as for most patients it was impossible to discriminate which part of the post-fracture home care and GP visits was actually due to the hip fracture and not due to care for other pre- or post-fracture conditions. With these limitations in mind the results of the current study are in line with previous international publications.

In conclusion, the treatment of displaced femoral neck fractures with hemi- or total hip arthroplasty is costly with mean total costs after one year of $€ 23,869$ and $€ 26,399$ after 2 years of follow-up. Rehabilitation and nursing homes account for almost half of the total medical costs, revision surgery, and adverse events not even $10 \%$. Focus on improvements of the rehabilitation phase can result in reducing costs.

Acknowledgments Steering Committee: Mohit Bhandari (Chair), PJ Devereaux, Thomas A. Einhorn, Lehana Thabane, Emil H. Schemitsch, Kenneth J Koval, Frede Frihagen, Rudolf W. Poolman, Kevin Tetsworth, Ernesto Guerra-Farfán, Stephen D. Walter, and Gordon H Guyatt.

Global Methods Centre: Mohit Bhandari (Principal Investigator); Sheila Sprague (Research Program Manager); Kim Madden, Paula McKay, Marilyn Swinton, and Taryn Scott, (Project Management); Diane Heels-Ansdell, (Statistical Analysis); and Lisa Buckingham and Aravin Duraikannan (Data Management) (McMaster University).

US Methods Centre: Thomas A. Einhorn (Principal Investigator) and Heather Silva (Research Coordination) (Boston University Medical Center).

Netherlands Methods Centre: Rudolf W. Poolman (Principal Investigator), Martin J. Heetveld (Co-Principal Investigator); Esther M.M. Van Lieshout (Research Coordination), and Paul T.P.W. Burgers (Trial Coordination) (Erasmus Medical Centre, Rotterdam).

Central Adjudication Committee: Mohit Bhandari (Chair), Robert D. Zura, Emil H. Schemitsch, Victoria Avram, Ajay Manjoo, and Dale Williams.

Data Safety Monitoring Board (CIHR): John Antoniou (Chair), Tim Ramsay, Earl R. Bogoch, and Andrew Trenholm.

Data Safety Monitoring Board (NIH): Stephen Lyman (Chair), Madhu Mazumdar, Kevin J. Bozic, Mark Luborsky, Stuart Goodman, and Susan Murray.

HEALTH Investigators

The following persons participated in the HEALTH trial:

Canada

University of Calgary, Foothills Medical Centre-Rob Korley, Richard Buckley, Paul Duffy, Shannon Puloski, Kimberly Carcary, Melissa Lorenzo, Georgia Carstensen, and Ross McKercher; University of Calgary, Rockyview General Hospital - Kelly Johnston, Greg Abelseth, Raul Kuchinad, and Saboura Mahdavi; St. Michael's Hospital-Emil H. Schemitsch, Michael D. McKee, Jeremy A. Hall, Aaron Nauth, Daniel Whelan, Timothy R. Daniels, Earl R. Bogoch, James P Waddell, Henry Ahn, Milena R. Vicente, Jennifer T. Hidy, and Melanie T. MacNevin; Sunnybrook Health Sciences Centre - Hans Kreder, Terry Axelrod, Richard Jenkinson, Markku Nousiainen, David Stephen, Veronica Wadey, Monica Kunz, Katrine Milner, Ria Cagaanan, and Melanie MacNevin; Vancouver General Hospital —Peter J. O'Brien, Piotr A. Blachut, Henry M. Broekhuyse, Pierre Guy, Kelly A. Lefaivre, Gerard P. Slobogean, Raman Johal, and Irene Leung; Queen Elizabeth II Health Sciences Centre - Chad Coles, Ross Leighton, C. Glen Richardson, Michael Biddulph, Michael Gross, Michael Dunbar, J. David Amirault, David Alexander, Catherine Coady, Mark Glazebrook, David Johnston, William Oxner, Gerald Reardon, Ivan Wong, Kelly Trask, and Shelley MacDonald; Memorial University of Newfoundland-Andrew Furey, Craig 
Stone, and Minnie Parsons; University of British Columbia/Fraser Health Authority - Trevor Stone, Mauri Zomar, Robert McCormack, Kelly Apostle, Dory Boyer, Farhad Moola, Bertrand Perey, Darius Viskontas, Karyn Moon, and Raely Moon; Hôpital du Sacré-Coeur de Montréal-Yves Laflamme, Benoit Benoit, Pierre Ranger, Michel Malo, Julio Fernandes, Karine Tardif, and Julie Fournier; Hôpital MaisonneuveRosemont-Pascal André Vendittoli, Vincent Massé, Alain G. Roy, Martin Lavigne, and Daniel Lusignan; Hôpital Saint-François d'AssiseEtienne L Belzile, and Pascale Levesque-Bernier; Hôpital de l'Enfant Jésus-Etienne L Belzile, Luc Bédard, and Pascale Levesque-Bernier; and Lakeridge Health - Samir Chhabra, Kelly Fusco.

\section{United States}

Colorado Orthopedic Consultants - Craig Davis, Philip Stull, Stewart Weinerman, Peter Weingarten, Steven Lindenbaum, Michael Hewitt, Rebecca Danielwicz, and Janell Baker; Rubin Institute for Advanced Orthopaedics-Michael Mont, Donald E. Delanois, Bhaveen Kapadia, Kimona Issa, and Marylou Mullen; Mayo Clinic-Andrew Sems and Barb Foreman; Rothman Institute- Javad Parvizi and Tiffany Morrison; Orthopaedic Associates of Hartford - Courtland Lewis and Stephanie Caminiti; Boston University Medical Center-Thomas A Einhorn, Paul Tornetta III, William R Creevy, Heather Silva, Michelle J. Lespasio, adn Hope Carlisle; Lahey Clinic-Andrew Marcantonio, Michael Kain, Lawrence Specht, and John Tilzey, and John Garfi; University of Pennsylvania - Samir Mehta, John L. Esterhai Jr, Jaimo Ahn, Derek Donegan, Annamarie Horan, and Kelly McGinnis; Emory University School of Medicine - James Roberson, Thomas Bradbury, Greg Erens, and Kyle Webb; Indiana University - Brian Mullis, Karl Shively, Andrew Parr, Janos Ertl, Ripley Worman, Mark Webster, Judd Cummings, Valda Frizzell, and Molly Moore; Orthopaedic Associates of Michigan - Clifford B. Jones, James R. Ringler, Debra L. Sietsema, and Jane E. Walker; Texas Tech University-Enes Kanlic, Amr Abdelgawad, and Juan Shunia; Mission Hospital Research InstituteCharles DePaolo, Susan Sutherland, and Rachel Alosky; Duke University Medical Center-Robert Zura and Maria Manson; Park Nicollet Institute - Gregg Strathy, Kathleen Peter, Paul Johnson, and Meaghan Morton; St. Elizabeth Health Center-James Shaer, Tyson Schrickel, Barbara Hileman, Marina Hanes, and Elisha Chance; Texas Institute for Hip and Knee Surgery - E. Matthew Heinrich, David Dodgin, and Michele LaBadie; University of California Irvine - David Zamorano, Martin Tynan, Ran Schwarzkopf, John A Scolaro, Ranjan Gupta, Samuel Bederman, Nitin Bhatia, Bang Hoang, Douglas Kiester, Neil Jones, Gregory Rafijah, Damon Alavekios, Jason Lee, Akshay Mehta, Steven Schroder, Tom Chao, Vincent Colin, Phuc (Phil) Dang, Stephen Keun Heng, Gregory Lopez, Samuel Galle, Sohrab Pahlavan, Duy L Phan, Minal Tapadia, Christopher Bui, Nickul Jain, Tyler Moore, Nathan Moroski, and Deeba Pourmand; University of Utah-Erik N. Kubiak, Jeremy Gililland, David Rothberg, Christopher Peters, Christopher Pelt, Ami R. Stuart, and Kirby Corbey; Marshall University - Franklin D. Shuler, James Day, Tigran Garabekyan, Felix Cheung, Ali Oliashirazi, Jonathon Salava, Linda Morgan, Timothy Wilson-Byrne, and Mary Beth Cordle; Allegheny Hospital-Timothy J Sauber, Edward Westrick, Robert Duerr, Michael Maher, and Traci Salopek; University Orthopaedic Associates-Carlos A Sagebien, David A Harwood, Stephen Kayiaros, and Patricia Seuffert; State University of New York at Buffalo (UBMD Orthopaedics and Sports Medicine) - Sridhar Rachala, Mark Anders, Christopher Mutty, Matthew Philips, Allison Cornwall, and Mary Bayers-Thering; and University of Arizona - Michael Dohm, and Cindy Fastje

\section{Netherlands}

Amphia Ziekenhuis - Leon H.G.J. Elmans, Joost A.A.M. van den Hout, Adrianus J.P. Joosten, Ad F.A. van Beurden, Stefan B.T. Bolder, Denise Eygendaal, Adrianus F.C.M. Moonen, Rutger C.I. van Geenen, Eric A. Hoebink, Robert Wagenmakers, and Wouter van Helden; Deventer Ziekenhuis-Ydo V Kleinlugtenbelt, HansPeter W. van Jonbergen, Herbert Roerdink, Joost M. Reuver, Alexander F.W. Barnaart, and Elvira R. Flikweert; Diaconessenhuis Leiden-
Rover Krips, J. Bernard Mullers, and Hans Schüller; Flevoziekenhuis-Mark L.M. Falke, Frans J. Kurek, and Adrianus C.H. Slingerland; Gelderse Vallei-Jan P. van Dijk and Wouter H. van Helden; Gelre Ziekenhuizen-Hugo W. Bolhuis, Pieter H.J. Bullens, Mike Hogervorst, Karin E . de Kroon, Rob H . Jansen, Ferry Steenstra, and Eric E.J. Raven; IJsselland Ziekenhuis-W. Peter J. Fontijne, Saskia C. Wiersma, Bastiaan Boetes, and Edgar J.T. ten Holder; Leids Universitair Medisch Centrum-Huub J.L. van der Heide, Jochem Nagels, and Enrike H.M.J. van der Linden-van der Zwaag; Medisch Centrum Haaglanden-Stefan B. Keizer, JanWillem A. Swen, Peter H.C. den Hollander, and Bregje J.W. Thomassen; $O L V G$-Rudolf W. Poolman, Willem Jan Kleyn Molekamp, Frank R.A.J. de Meulemeester, Arthur E.B. Kleipool, Robert Haverlag, Maarten P. Simons, and Eduard L.A.R. Mutsaerts; Ruwaard van Putten Ziekenhuis-Rob Kooijman, Roelf R. Postema, René J.T.M. Bleker, and Harald I.H. Lampe; SlotervaartziekenhuisLein Schuman, John Cheung, Frank van Bommel, W. Paul C.A. Winia, Daniel Haverkamp, and Harm van der Vis; Spaarne Ziekenhuis-Peter A. Nolte, Michel P.J. van den Bekerom, Tjitte de Jong, Arthur van Noort, Diederik A. Vergroesen, and Bernard G. Schutte; and Tergooiziekenhuizen-Harm M . van der Vis, Lijkele Beimers, Jasper de Vries, Arthur W. Zurcher, G.H. Rob Albers, Maarten Rademakers, Stefan Breugem, Ibo van der Haven, Pieter Jan Damen, Gythe H. Bulstra, Martin M. Campo, Mathijs P. Somford, and Daniël Haverkamp.

\section{International}

The Alfred - Susan Liew, Harvinder Bedi, Ashley Carr, Andrew Chia, Steve Csongvay, Craig Donohue, Stephen Doig, Elton Edwards, Max Esser, Richard Freeman, Andrew Gong, Doug Li, Russell Miller, Lu Ton, Otis Wang, Ian Young, Adam Dowrick, Zoe Murdoch, and Claire Sage; Oslo University Hospital - Frede Frihagen, Lars Nordsletten, John Clarke-Jenssen, Geir Hjorthaug, Anne Christine Brekke, and Elise Berg Vesterhus, Ringerike Sykehus Hospital_-Ingunn Skaugrud; Hospital Universitario Costa del Sol-Enrique Guerado, Encarnacion Cruz, and Juan Ramon Cano; Hospital Dr. Josep Trueta-Miguel Angel Froufe, Lluis Marull Serra, Samer Al-dirra, and Cristina Martinez; The Geelong Hospital - Richard Page, David Bainbridge, Richard Angliss, Ben Miller, Andrew Thomson, Graeme Brown, Simon Williams, Kevin Eng, David Bowyer, John Skelley, Chatar Goyal, and Sally Beattie; Hospital de la Ribera - Francisco José Tarazona Santabalbina; Vall d'Hebron University Hospital-Ernesto Guerra-Farfán, Jordi Teixidor Serra, Jordi Tomas Hernandez, Marc Aguilar Garcia, Vicente Molero Garcia, Sergi Barrera, Jordi Selga, Teresa Sanclemente, Maria Villar, Joan Bago, and Miriam Garrido; James Cook University Hospital-Amar Rangan, Birgit Hanusch, Lucksy Kottam; North Shore Hospital-William Farrington and Carol Greene; and University Hospital 12 de Octubre-José A Moreno Beamud, Pedro Caba Doussoux, Rafael Navarro, Arantxa Capel, and Emilio Delgado

\section{Compliance with ethical standards}

\section{Conflicts of interest None.}

Ethical approval All procedures performed in studies involving human participants were in accordance with the ethical standards of the institutional and/or national research committee and with the $1964 \mathrm{Hel}-$ sinki declaration and its later amendments or comparable ethical standards.

Funding Members of the research team received a grant from The Netherlands Organization for Health Research and Development (ZonMw; grant number 17088.2503), Canadian Institutes of Health Research (CIHR; grant number MCT-90168) and National Institutes of Health (NIH; grant number 1R011AR055130-01A1). The funding agencies were not involved in the study design, data collection, data analysis, manuscript preparations or publication decisions for this manuscript. 
Open Access This article is distributed under the terms of the Creative Commons Attribution-NonCommercial 4.0 International License (http:// creativecommons.org/licenses/by-nc/4.0/), which permits any noncommercial use, distribution, and reproduction in any medium, provided you give appropriate credit to the original author(s) and the source, provide a link to the Creative Commons license, and indicate if changes were made.

\section{References}

1. Cooper C, Campion G, Melton LJ 3rd (1992) Hip fractures in the elderly: a world-wide projection. Osteoporos Int 2(6):285-289

2. Gullberg B, Johnell O, Kanis JA (1997) World-wide projections for hip fracture. Osteoporos Int 7(5):407-413

3. http://statline.cbs.nl/StatWeb/publication/?DM=SLNL\&PA= 71859NED\&D1 $=4 \& \mathrm{D} 2=0 \& \mathrm{D} 3=0 \& \mathrm{D} 4=157 \& \mathrm{D} 5=\mathrm{a} \& \mathrm{HDR}=$ $\mathrm{T}, \mathrm{G} 1 \& \mathrm{STB}=\mathrm{G} 2, \mathrm{G} 3, \mathrm{G} 4 \& \mathrm{CHARTTYPE}=1 \& \mathrm{VW}=\mathrm{T}(2014)$.

4. http://www.nhfd.co.uk/20/hipfractureR.nsf/welcome?readform (2013).

5. Garden R (1961) Low-angle fixation in fractures of the femoral neck. J Bone Joint Surg (Br) 43:647-663

6. http://www.shpr.se/Libraries/Documents/\%C3\%85rsrapport 2011 eng webb.sflb.ashx (2011).

7. Bhandari M, Devereaux PJ, Tornetta P 3rd, Swiontkowski MF, Berry DJ, Haidukewych G, Schemitsch EH, Hanson BP, Koval K, Dirschl D, Leece P, Keel M, Petrisor B, Heetveld M, Guyatt GH (2005) Operative management of displaced femoral neck fractures in elderly patients. An international survey. J Bone Joint Surg Am 87(9):2122-2130. doi:10.2106/JBJS.E.00535

8. Iorio R, Healy WL, Lemos DW, Appleby D, Lucchesi CA, Saleh KJ (2001) Displaced femoral neck fractures in the elderly: outcomes and cost effectiveness. Clin Orthop Relat Res 383:229-242

9. Johansson T, Bachrach-Lindstrom M, Aspenberg P, Jonsson D, Wahlstrom O (2006) The total costs of a displaced femoral neck fracture: comparison of internal fixation and total hip replacement. A randomised study of 146 hips. Int Orthop 30(1):1-6. doi:10. 1007/s00264-005-0037-z

10. Keating JF, Grant A, Masson M, Scott NW, Forbes JF (2006) Randomized comparison of reduction and fixation, bipolar hemiarthroplasty, and total hip arthroplasty. Treatment of displaced intracapsular hip fractures in healthy older patients. J Bone Joint Surg Am 88(2):249-260. doi:10.2106/JBJS.E.00215

11. Waaler Bjornelv GM, Frihagen F, Madsen JE, Nordsletten L, Aas E (2012) Hemiarthroplasty compared to internal fixation with percutaneous cannulated screws as treatment of displaced femoral neck fractures in the elderly: cost-utility analysis performed alongside a randomized, controlled trial. Osteoporos Int 23(6):1711-1719. doi: 10.1007/s00198-011-1772-1

12. http://www.kostenvanziekten.nl/systeem/kosten-van-ziekten-tool/ Default.aspx?ref=kvz_v211b1p4r7c3i0t 1 j0o 2 y 0 a1g0d100s54z0f0w2 (2013).

13. Allan GM, Lexchin J (2008) Physician awareness of diagnostic and nondrug therapeutic costs: a systematic review. Int J Technol Assess Health Care 24(2):158-165. doi:10.1017/S0266462308080227

14. Chesser TJ, Ya'ish F (2013) Should surgeons know the costs of the implants they use? Injury 44(10):1261-1262. doi:10.1016/j.injury. 2013.06.026
15. Streit JJ, Youssef A, Coale RM, Carpenter JE, Marcus RE (2013) Orthopaedic surgeons frequently underestimate the cost of orthopaedic implants. Clin Orthop Relat Res 471(6):1744-1749. doi:10. 1007/s11999-012-2757-x

16. Zielinski SM, Bouwmans CA, Heetveld MJ, Bhandari M, Patka P, Van Lieshout EMM (2014) The societal costs of femoral neck fracture patients treated with internal fixation. Osteoporos Int 25(3): 875-885. doi:10.1007/s00198-013-2487-2

17. Hakkaart-van Roijen L (2002) Manual Trimbos/iMTA questionnaire for costs associated with psychiatric illness (in Dutch). Institute for Medical Technology Assessment, Rotterdam

18. http://www.bmg.eur.nl/fileadmin/ASSETS/bmg/english/iMTA/ Publications/Manuals_Questionnaires/Vragenlijsten_2013/ Questionnaire_TiC-P_initial_version_in_English.pdf.

19. Hakkaart-van Roijen L, Tan, S.S., Bouwmans, C.A.M. (ed) (Geactualiseerde versie 2010.) Handleiding voor kostenonderzoek, methoden en standaard kostprijzen voor economische evaluaties in de gezondheidszorg. College voor zorgverzekeringen.

20. Rubin DB, Schenker N (1991) Multiple imputation in health-care databases: an overview and some applications. Stat Med 10(4): 585-598

21. Briggs AH, Wonderling DE, Mooney CZ (1997) Pulling costeffectiveness analysis up by its bootstraps: a non-parametric approach to confidence interval estimation. Health Econ 6(4):327340. doi:10.1002/(SICI)1099-1050(199707)6:4<327::AIDHEC282>3.0.CO;2-W

22. Slover J, Hoffman MV, Malchau H, Tosteson AN, Koval KJ (2009) A cost-effectiveness analysis of the arthroplasty options for displaced femoral neck fractures in the active, healthy, elderly population. J Arthroplasty 24(6):854-860. doi:10.1016/j.arth.2008.05. 008

23. Alolabi B, Bajammal S, Shirali J, Karanicolas PJ, Gafni A, Bhandari M (2009) Treatment of displaced femoral neck fractures in the elderly: a cost-benefit analysis. J Orthop Trauma 23(6):442446. doi:10.1097/BOT.0b013e31817614dd

24. Frihagen F, Waaler GM, Madsen JE, Nordsletten L, Aspaas S, Aas E (2010) The cost of hemiarthroplasty compared to that of internal fixation for femoral neck fractures. 2-year results involving 222 patients based on a randomized controlled trial. Acta Orthop 81(4):446-452. doi:10.3109/17453674.2010.492763

25. Haentjens P, Autier P, Barette M, Boonen S (2003) Costs of care after hospital discharge among women with a femoral neck fracture. Clin Orthop Relat Res 414:250-258. doi:10.1097/01.blo. 0000079262.91782 .04

26. Nurmi I, Narinen A, Luthje P, Tanninen S (2003) Cost analysis of hip fracture treatment among the elderly for the public health services: a 1-year prospective study in 106 consecutive patients. Arch Orthop Trauma Surg 123(10):551-554. doi:10.1007/s00402-0030583-Z

27. Rogmark C, Carlsson A, Johnell O, Sembo I (2003) Costs of internal fixation and arthroplasty for displaced femoral neck fractures: a randomized study of 68 patients. Acta Orthop Scand 74(3):293298. doi:10.1080/00016470310014210

28. De Laet CE, van Hout BA, Burger H, Weel AE, Hofman A, Pols HA (1999) Incremental cost of medical care after hip fracture and first vertebral fracture: the Rotterdam study. Osteoporos Int 10(1): 66-72. doi:10.1007/s001980050196 